\title{
An Investigation of Soil Volume Changes at Four Dimensional Points of Peat Soil Sample in Parit Nipah and Pontian
}

\section{Adnan bin Zainorabidin ${ }^{1, a^{*}}$, Nursyahidah binti Saedon ${ }^{2, b}$, Ismail bin Bakar ${ }^{3, c}$ Nurul Farhana bt Mohd Seth ${ }^{2, d}$}

\author{
${ }^{1}$ Assoc, Prof. Dr., Faculty of Civil and Environmental Engineering, Universiti Tun Hussein Onn \\ Malaysia, Batu Pahat, Johor, Malaysia \\ ${ }^{2}$ Research student, Faculty of Civil and Environmental Engineering, Universiti Tun Hussein Onn \\ Malaysia, Batu Pahat, Johor, Malaysia \\ ${ }^{3}$ Prof. Emeritus Dr., Faculty of Civil and Environmental Engineering, Universiti Tun Hussein Onn \\ Malaysia, Batu Pahat, Johor, Malaysia \\ aadnanz@uthm.edu.my, ㅁnursyahidah.saedon@yahoo.com, 'bismail@uthm.edu.my \\ dennysfara@gmail.com
}

Keywords: peat soil, undisturbed sample, linear shrinkage, 4 dimensional points

\begin{abstract}
Peat soils occur in many countries and formed naturally through the decomposition of plant and animal matter. These soils are known as a very problematic soft soil due to its low bearing capacity and high compressibility. These two main factors may be based on the characteristics of the soil itself. This study is focused on its physical properties and shrinkage measurement. It is also to investigate the shrinkage measurement that obtained from the diameter at four dimensional points and bar linear shrinkage method for both location peat sample. There are varies method that can be used in order to obtain a full description of the shrinkage behavior of peat. The sample was taken from two different locations which are Parit Nipah and Pontian. Linear shrinkage method is used to determine the soil shrinkage from linear measurements on a bar mould with disturbed soil that passing $0.425 \mathrm{~mm}$ sieve. However, this method was modified by using undisturbed sample to compare the result with bar linear shrinkage method and the measurement was obtained by the reduction of its diameter at four points of the sample. Linear shrinkage values obtained from Parit Nipah and Pontian by following British Standard method are 34.77\% and 33.09\% respectively while modified linear method gives the value of $35.25 \%$ for Parit Nipah and $32.85 \%$ for Pontian. Modified method shows that peat soil from both locations shrinks in irregular shape due to Point C of Parit Nipah and Pontian peat sample has the smallest diameter compared to other points within 24 hours oven-dried. It also shows that Parit Nipah peat soil has a higher percentage of linear shrinkage for both method instead of Pontian peat soil. The linear shrinkage values that obtained from bar linear shrinkage and modified linear shrinkage gives smaller different values which is nearly same for both method.
\end{abstract}

\section{Introduction}

In civil engineering, there are many construction problems related to the development on soft soil areas especially peat soil area. According to soil taxonomy, peat consists of three organic matter decomposition stages that are fibric, hemic and sapric. This type of soil is also considered as most problematic soil due to its low bearing capacity and very high compressibility. There are two main factors poses as a challenge to engineers when they deal with this type of soil [1].

Peat soil areas can be found in South East Asia about two thirds of 30 million hectares [1]. [2] stated that there are more than three million hectares of peat and organic soil areas in Malaysia which consists of $8 \%$ from the total areas. Before beginning with any construction works, the study on shrinkage behavior of peat soil has to be conducted in order to avoid any failure in future development. There are several tests can be determined the shrinkage measurement of soil. Linear shrinkage and shrinkage limit is one of testing that can be conducted. This study is focused on the shrinkage tests on peat samples from two different locations in the state of Johore. 
Due to the rapid development of infrastructure in Malaysia, the construction on peat soil areas have to be stabilized and implemented. The construction of roadways and structure on peat soil will always be exposed to enormous deposition and unstable condition. The shrinkage characteristics of peat soil may lead to the failure of a structure.

\section{Purpose and Scope of Study}

The purposes of this study is to investigate its physical properties and shrinkage measurement that obtained from the diameter at four dimensional points and bar linear shrinkage method. It is also to compare the shrinkage behavior of peat soil in two different locations.

The study towards shrinkage behavior of peat soil was conducted on undisturbed samples from Parit Nipah and Pontian. All the samples were collected at $0.5 \mathrm{~m}$ depth from the top surface of soil. The tests that involved in this study are linear shrinkage method that according to BS1377: Part 1:1990 that had been modified which compatible with real phenomenon. All these tests were conducted at Research Centre for Soft Soils (RECESS), Universiti Tun Hussein Onn Malaysia.

\section{Literature Review on Peat Soil and Linear Shrinkage}

Peat Soil Definition. The definition of peat varies between soil science and engineering as well as different countries. According to the soil scientists, peat soil has an organic content more than 35\%, whilst geotechnical engineers stated that all the soils with organic content larger than $20 \%$ is known as organic soil. Peat soil is an organic soil which has organic content more than $75 \%$ [3].

The organic contents classified as peat are basically remains of plant whose rate of accumulation is faster than the rate of decay. The content of peat soils differs from locations due to the factors such as temperature and degree of humification. Decomposition or humidification involves the loss of organic matter either in gas or solution, the disappearance of physical structure and change in chemical state [3].

Based on fiber content classification, peat is divided into three groups that are fibric, hemic and sapric. Fibrous peat has a high organic and fiber content with a low degree of humification. It is consists of undecomposed fibrous organic materials, easily identifiable and extremely acidic meanwhile sapric peat contains highly decomposed materials. Peat may be classified on the basis of their degree of decomposition. The scale used is known as 'Von Post Classification' which conventionally divides peats into ten classes, named $\mathrm{H} 1$ to $\mathrm{H} 10$ [2].

Table 1 : Classification of peat soil [2]

\begin{tabular}{|c|c|c|}
\hline Types of peat & Fiber content (\%) & Von Post Scale \\
\hline Fibric & More than 66 & H1 to H4 \\
\hline Hemic & $33-66$ & H5 to H6 \\
\hline Sapric & Less than 33 & H7 to H10 \\
\hline
\end{tabular}

Physical Properties of Peat. There are a few unique physical properties of peat, which should be taken into account when discussing on peat soil. As referred in [2], the physical characteristics such as colour, degree of humification, water content and organic content should be included in a full description of peat.

Degree of humification represents the degree of organic content that had decayed. Organic content is a measurement of peat purification from any mineral component and it is important to the classification of peat and related to the morphology of peat deposition. In West Malaysia, the moisture content ranges from 200 to $700 \%$ [2].

Meanwhile, specific gravity of peat is greatly affected by its composition and percentage of inorganic component. Degree of decomposition and mineral content will increased due to increase of specific gravity. Peat is known as high organic content which is $75 \%$ and above while the value of specific gravity is in the range 1.3 to 1.8 [2]. 
Mechanical Properties of Peat. An important characteristics of organic soils is the shrinkage that accompanies the drainage and the resulting decrease of the base volume. It has to differentiate between the irreversible and the reversible shrinkage. Moreover, in strongly drained fen peat soils, high evaporation rates can lead to reversible shrinkage cracks and clefts [4].

The shrinkage of the soil material, especially the initial shrinkage, leads to strong alterations of the special pore structure [5]. Peat will shrink when it gets dry and the shrinkage could reach 50\% of the initial volume. However, the dried peat will not swell up upon saturation due to incapability of dried peat to absorb water as much as initial condition; only 33 to $55 \%$ of water can be reabsorbed [2]. The common value of shrinkage is in the range of $20-40$ in West Malaysia as referred in [6].

\section{Materials and Methods}

Some past research had been reviewed to provide rationale data of the study and to give some information on the physical properties of the peat soil. This study was focused on shrinkage behavior of peat soils. It is determined by two different linear shrinkage method which are bar linear shrinkage that followed by British Standard and modified linear shrinkage which is more compatible with real phenomenon due to non-homogeneity particle in peat soil.

Bar linear method was used disturbed sample that passing $425 \mu \mathrm{m}$ wet sieving. The shrinkage mould filled by sample with linear measurement of $139 \mathrm{~mm}$ was first placed open aired until the soil has shrunk away from the walls of the moulds. Then, it is placed in the oven at temperature not exceeding $65^{\circ} \mathrm{C}$ until shrinkage has largely ceased, and lastly at $105^{\circ} \mathrm{C}$ oven-dried to complete the drying process.

However, modified linear method was conducted an undisturbed peat samples by placing the mould with sample directly into $105^{\circ} \mathrm{C}$ oven-dried within 24 hours. An undisturbed sample with diameter approximately $75 \mathrm{~mm}$ and $20 \mathrm{~mm}$ height was used in this method. The diameter changes was measured by point A, B, C and D as illustrated in Fig. 1. The reading of soil shrinkage for both method was taken at $0.5,1,2,4,6,20$ and 24 hours. All these laboratory tests procedure are followed BS1377-2 : 1990 except for modified shrinkage method. The data obtained was analyzed and compared with previous study to make a conclusion.

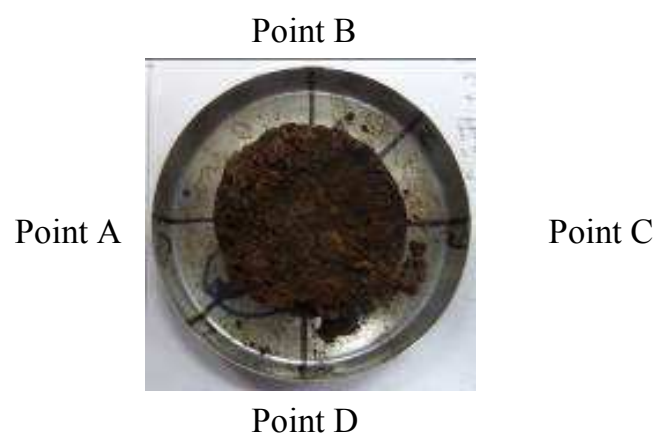

Fig. 1 : Modified Shrinkage Measurement

The methodology of the study is summarized in flowchart as shown in Fig. 2. This is an experimental study, which focus on the determination of shrinkage behavior of the peat soil from two different locatons which are Parit Nipah and Pontian. 


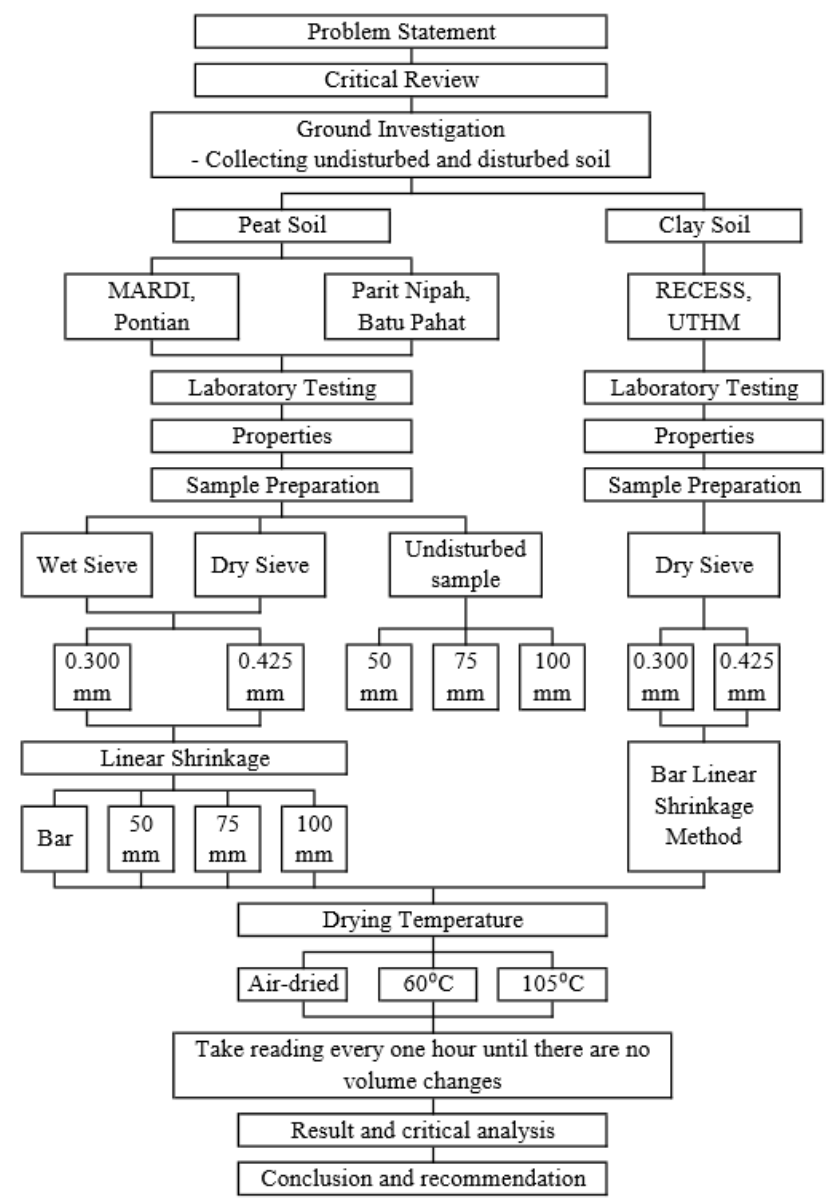

Fig. 2 : Flow chart of the study

\section{Results and Discussions}

Moisture Content and Fiber Content. Moisture content expressed the amount of water present in a moist sample which the water can be removed from the soil by drying at $105^{\circ} \mathrm{C}$. The average value of moisture content obtained for peat soil in Parit Nipah and Pontian were 701\% and 658\% respectively. These values satisfactory with the moisture content range values of West Malaysia is peat which is $200-700 \%$ based on [2]. The value of fiber content for peat soil in Pontian was $38.65 \%$ while for Parit Nipah peat is $40.97 \%$. It shows that Parit Nipah and Pontian peat soil were categorized as hemic peat.

Organic Content. The value of organic content is usually determined from the loss of ignition test as a percentage of oven-dried mass. From the test that have been conducted, organic content value obtained for Parit Nipah peat soil is $89.87 \%$ while the organic content for Pontian peat soil is $75.45 \%$. It can be concluded that the organic content of Parit Nipah was higher than Pontian but it is still in the ranges of organic content values for West Malaysia which is 65-97\% [2].

Specific Gravity. The average value of specific gravity that obtained from Parit Nipah and Pontian were 1.43 and 1.62 respectively which is in the ranges of specific gravity for West Malaysia peat which is 1.38 to 1.70 [2].

Linear Shrinkage. The linear shrinkage of peat soil was determined by using two different methods. First method is linear Shrinkage Limit test according to BS1377-2 and another method was called as modified linear method with directly placing the sample into $105^{\circ} \mathrm{C}$ oven-dried. This method was conducted in order to determine the linear shrinkage of the fraction of a soil sample that passing $425 \mu \mathrm{m}$ test sieve from linear measurements on a bar of soil. 
Bar Linear Shrinkage. The values of linear shrinkage that obtained from linear method that followed to British Standard are 34.77\% and 33.09\% for Parit Nipah and Pontian respectively.

Modified Linear Shrinkage. Modified linear shrinkage test was conducted in order to show that the linear shrinkage value of peat samples can be determined in various methods. In this study, undisturbed samples is used in this testing in order to make it compatible with real phenomenon. The measurement of the shrinking soil sample was measured by point $\mathrm{A}, \mathrm{B}, \mathrm{C}$ and $\mathrm{D}$ and the shrinkage behavior was determined by $105^{\circ} \mathrm{C}$ of drying temperature. The modified linear shrinkage method gave the value of $35.25 \%$ for Parit Nipah peat sample and $32.85 \%$ for Pontian peat sample. According to the previous study, these values are in the range of shrinkage for West Malaysia peat which is in range $20-40 \%$ [6].

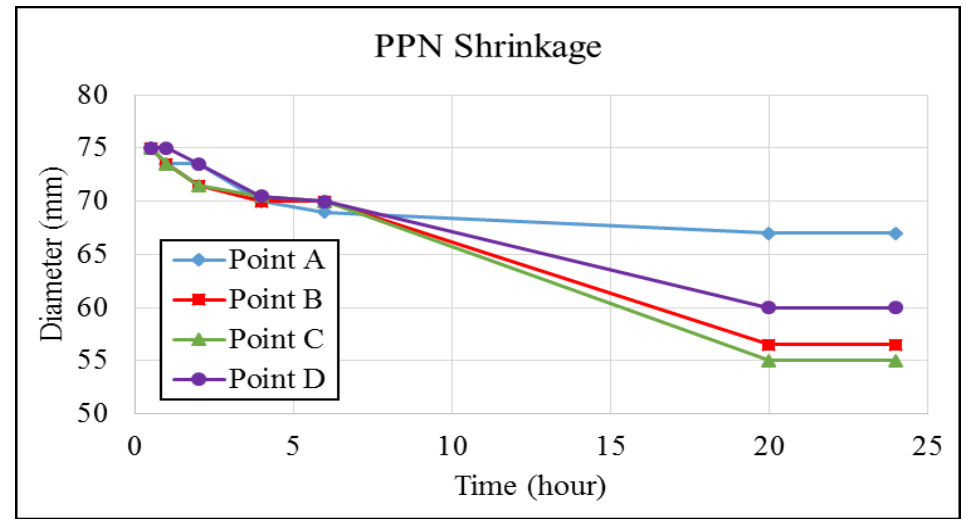

Fig. 3 : Diameter of Parit Nipah peat sample in $105^{\circ} \mathrm{C}$ for 24 hours

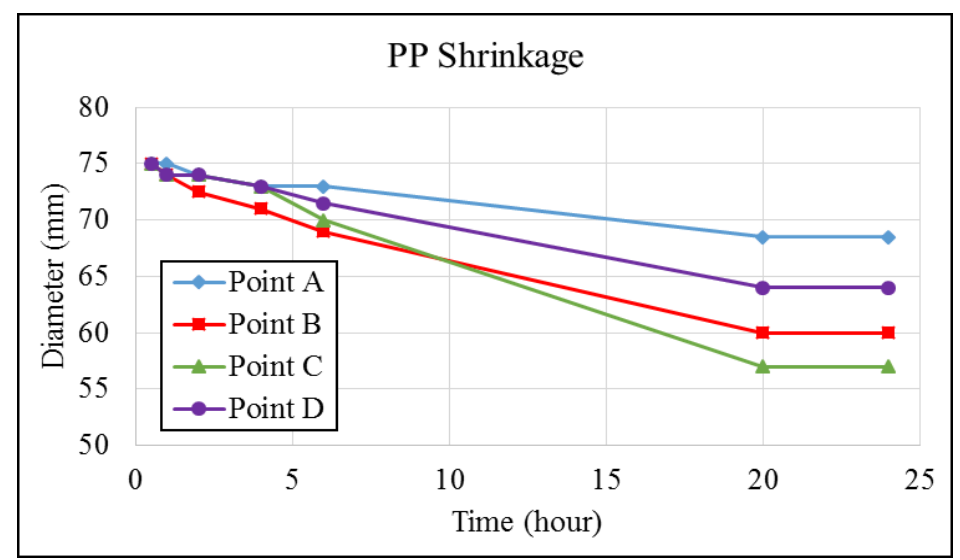

Fig. 4 : Diameter of Pontian peat sample in $105^{\circ} \mathrm{C}$ for 24 hours

Fig. 3 and Fig. 4 shows that Point $\mathrm{C}$ of Parit Nipah and Pontian peat sample has the smallest diameter compared to other points. The greatest shrinkage measurement for both samples were shown after 6 hours oven-dried. It shows that the optimm shrinkage of the peat soil occurred when the surrounding temperature was high and reached its shrinkage limit within 20 hours. After the period, there are no any changes to the diameter of the peat soil specimen.

The diameter value of sample is directly proportional to the volume of sample. The volume will decrease if the diameter value were decreased. The volume of peat sample for both locations were higher when it wet and started to decrease as the soil sample was dried and shrunk. It is also shows that the shrinkage parameter is variable due to non-homogeneity particles. The diameter changes of sample from four points during shrinkage testing were different. Table 2 shows the summary of data for all tests that had been conducted. Modified shrinkage data was obtained from the average of four points measurement. 
Table 2 : Summary of the data

\begin{tabular}{|c|c|c|c|c|c|c|}
\hline \multirow{2}{*}{$\begin{array}{l}\text { Laboratory } \\
\text { Tests }\end{array}$} & \multirow{2}{*}{$\begin{array}{l}\text { Moisture } \\
\text { Content }\end{array}$} & \multirow{2}{*}{$\begin{array}{c}\text { Fiber } \\
\text { Content }\end{array}$} & \multirow{2}{*}{$\begin{array}{l}\text { Specific } \\
\text { Gravity }\end{array}$} & \multirow{2}{*}{$\begin{array}{l}\text { Organic } \\
\text { Content }\end{array}$} & \multicolumn{2}{|c|}{$\begin{array}{c}\text { Linear Shrinkage } \\
\text { Method }\end{array}$} \\
\hline & & & & & Bar & Modified \\
\hline $\begin{array}{c}\text { Parit Nipah } \\
\text { peat soil } \\
\text { (PPN) }\end{array}$ & $701 \%$ & $40.97 \%$ & 1.43 & $89.87 \%$ & $34.77 \%$ & $35.25 \%$ \\
\hline $\begin{array}{l}\text { Pontian peat } \\
\text { soil (PP) }\end{array}$ & $658 \%$ & $38.65 \%$ & 1.62 & $75.45 \%$ & $33.09 \%$ & $32.85 \%$ \\
\hline
\end{tabular}

\section{Conclusions}

From this study, it can be concluded as follows :
a) The study of peat soils behaviour from two different locations had been obtained from the determination of its physical properties and shrinkage measurements of the soil.
b) Parit Nipah peat soil has a higher percentage of linear shrinkage for both method instead of Pontian peat soil.
c) The linear shrinkage values that obtained from bar linear shrinkage and modified linear shrinkage gives smaller different values which is nearly same for both method.
d) All of the values obtained are satisfactory with the previous literature.
e) The shrinkage measurement during drying process influenced the volume of peat soil as the volume decreases when the soil shrunk. It is also shows that there are no volume changes during drying process within 24 hours.

\section{Acknowledgement}

The special acknowledgement to beloved supervisor, Assoc. Prof. Dr. Adnan bin Zainorabidin for big support and supervision during my study and completion of this paper. Not forgotten to Prof. Dato' Dr. Ismail Bakar who had guiding me and this research was funded by Malaysian Technical University Network (MTUN), Centre of Excellent (CoE) Grant Vot C012 with title 'Soft Soil Engineering and its Challenging Ground', Universiti Tun Hussein Onn Malaysia.

Heartfelt acknowledgements are expressed to my beloved family. Also, thanks to Research Centre of Soft Soils (RECESS), UTHM staff in guiding and providing laboratory facilities.

\section{References}

[1] M.N. Mohidin@Mohyeddin,, A. Zainorabidin, , A. Madun, , M.F. Yusof, , M. Mokhtar, \& . Chew,. Some index properties on Rengit peat soil stabilize with cement-lime, Prosiding Kebangsaan Awam '07, Langkawi, Kedah, (2007).

[2] B.K. Huat, , Organic and peat soil engineering, Universiti Putra Malaysia. Ampang Press Sdn. Bhd., (2004).

[3] S. Kazemian, and B.K. Huat, , Compressibility characteristics of fibrous tropical peat reinforced with cement column. Electronic J. Geotech. Eng. 14E (2009) pg. 1-8.

[4] C.J Schothorst,.., Drainage and behavior of peat soils, Proc. Symp. on peatlands below the sea level, Wegeningen, (1982).

[5] K. Schwarzel, , M. Renger, , R. Sauerbey, and G. Wessolek, , Soil physical characteristics of peat soils, J. Plant Nutr. Soil Science, 165, (2002) pg. 479-486.

[6] R. Hashim, and M.S. Islam, , A model study to determine engineering properties of peat soil and effect on strength after stabilization, European Journal of Scientific Research, Vol. 22, No. 2 (2008) pg. 205-215. 